\title{
Prevalence of Hypogonadism in a Male Population below 60 Years of Age with Metabolic Syndrome
}

\author{
Rafael Ríos, ${ }^{1}$ Natalia Jara, ${ }^{2}$ Bernardita Ratkman, ${ }^{3}$ Alejandra Valenzuela, ${ }^{4}$ \\ Carla Palavecino, ${ }^{4}$ and José Manuel Ortuya ${ }^{4}$ \\ ${ }^{1}$ Department of Endocrinology, University of Chile, San Borja Arriaran Hospital, Santiago, Chile \\ ${ }^{2}$ Department of Medicine, University of Chile, San Borja Arriaran Hospital, Santiago, Chile \\ ${ }^{3}$ Vespucio Clinic, Santiago, Chile \\ ${ }^{4}$ University of Chile, Santiago, Chile
}

Correspondence should be addressed to Rafael Ríos; rafaelrios1292@gmail.com

Received 12 January 2015; Revised 21 May 2015; Accepted 25 May 2015

Academic Editor: Gaffari Türk

Copyright (C) 2015 Rafael Ríos et al. This is an open access article distributed under the Creative Commons Attribution License, which permits unrestricted use, distribution, and reproduction in any medium, provided the original work is properly cited.

\begin{abstract}
Introduction. A high prevalence of hypogonadism $(\mathrm{H})$ has been demonstrated in patients with metabolic syndrome (MetS). There are no studies in Latin America showing the prevalence of $\mathrm{H}$ in MetS in men below 60 years of age. The objective of this study was to determine the association between the MetS and levels of testosterone (T) and calculated free testosterone (cfT) in men under 60 years of age. Methodology. 101 men were included between 18 and 60 years who met the IDF MetS criteria. The diagnosis of H was considered $<70 \mathrm{pg} / \mathrm{mL}$ of $\mathrm{cfT}$ and $<10.4 \mathrm{nmol} / \mathrm{L}(300 \mathrm{ng} / \mathrm{dL})$ of T. Results. $\mathrm{H}$ with T was $17.8 \%$ and $20.7 \%$ with cf T. The $\mathrm{H}$ according to $\mathrm{T}$ had higher BMI, waist circumference, visceral fat, markers of insulin resistance, SHBG, LH, and E2. We find an inverse but weak significant correlation between T, visceral fat, and HOMA index. The linear regression analysis showed that E2 and visceral fat are determinants in $\mathrm{H}$. Conclusion. We found a high prevalence of $\mathrm{H}$ using $\mathrm{T}$ and cfT in Chilean patients with MetS below 60 years of age, who turned out to be more insulin-resistant and have more visceral fat, waist, and $\mathrm{E} 2$ than non- $\mathrm{H}$.
\end{abstract}

\section{Introduction}

The metabolic syndrome (MetS) corresponds to a series of alterations that establish an association between high blood pressure (HBP), glucose intolerance, elevated triglycerides (TGS), and reduction of high density lipoprotein (HDL) cholesterol, which determines a higher risk of developing cardiovascular disease and diabetes [1]. There is a high prevalence of MetS worldwide [2], despite the fact that the diagnostic criteria are not uniform [3]. Latin American urban populations do not escape this reality since they exhibit a high prevalence of abdominal obesity, with a consequent increase in cardiovascular risk and development of Type 2 Diabetes Mellitus (T2DM) [4]. Some genetic variations aggravated by environmental factors (sedentary lifestyle, inadequate nutrition, and migration) have been claimed as major etiological factors of this condition [5]. In our country, a study with data obtained from the National Health Survey (ENS) in 2003 determined the prevalence of MetS, in the adult Chilean population, to be $31.6 \%$ and $36.8 \%$ based, respectively, on updated ATP III and IDF criteria [6]. Furthermore, epidemiological studies have reported consistently a high prevalence of low testosterone (T) levels in men with MetS and T2DM compared to the general population, of even up to $50 \%$ of hypogonadism $(\mathrm{H})$ in men with a diagnosis of T2DM $[7,8]$. The etiopathogenesis is not yet clear, but the role of abdominal obesity and the increase in visceral fat have been highlighted as a common and essential pathophysiological element [5].

It is unclear whether visceral fat determines an effect on the hypothalamic level, the testicular level (Leydig cells), or a combination of both [9], although apparently the $\mathrm{H}$ is a factor that precedes the MetS, which is why in recent years the studies showing this important association have multiplied $[10,11]$.

$\mathrm{H}$ in men, defined as a deficit of $\mathrm{T}$ associated or not with symptoms, is considered a CVD risk factor $[12,13]$. With age, 
there is a significant drop in T [14]; however in men under 60 years old, the fall does not occur in a relevant way, unless there are concomitant factors that accelerate it, such as diabetes, obesity, and chronic and metabolic diseases $[11,15,16]$.

There are no studies of hypogonadism associated with MetS in populations younger than 60 years in Chile and Latin America, so that we decided to conduct a study to determine the prevalence of this association in an urban Chilean population, determining anthropometric, metabolic, and hormonal variables.

\section{Methodology}

We recruited patients who sought preventive medical checkups or management of malnutrition due to excess, at a private medical center affiliated to a health insurance and a university. For this study, male patients aged between 18 and 60 years, with a BMI less than 40 , being sedentary, and meeting criteria of metabolic syndrome according to IDF 2005 [17] were considered. Patients who had a history of diabetes mellitus, uncompensated hypothyroidism, tumors, surgery or radiation in the hypothalamic-pituitary area, anosmia, liver, kidney or heart disease, cancer, neuroleptic or tricyclic/IRSS use, or hormone replacement therapy (HRT) with $\mathrm{T}$ were excluded from the study. All patients signed informed consent approved by local ethic committee.

At the day of assessment, with 8 hours fasting, the following measurements were performed: anthropometry (weight, height, BMI, blood pressure, and waist circumference) and analysis of body composition (percentage of muscle, body fat, and visceral fat) with a bioimpedanciometry device, OMRON model HBF $510[18,19]$ and biochemical analysis consisting of glycaemia and basal and postload insulinemia (used to calculate insulin sensitivity indices: HOMA and QUICKI), lipid panel, prolactin, TSH, total testosterone, LH, SHBG, and estradiol (E2). Free testosterone ( $\mathrm{cfT}$ ) was calculated using the Vermeulen formula [20,21].

Laboratory tests were conducted by the chemiluminescence method, with BIORAD trial (Immunoassay-MCC1, MCC2, and MCC3 Liquid) for T and SHBG and BIORAD (Immunoassay Plus) for LH, TSH, Prolactin, E2, and lipids. Both kits were with an intertrial variability of less than $10 \%$. Those patients with elevated levels of $\mathrm{LH}$ and prolactin were excluded from the analysis. The diagnosis of $\mathrm{H}$ was considered to be below $70 \mathrm{pg} / \mathrm{mL}$ of cf T [22] and T less than $10.4 \mathrm{nmol} / \mathrm{L}(300 \mathrm{mg} / \mathrm{dL})$, based on reference data from the published literature [23-26].

2.1. Statistical Analysis. The normality of variable distribution was determined using the Shapiro Wilk test. Variables with a normal distribution are expressed as mean \pm standard deviation. Variables with a nonnormal distribution are expressed as median (p25-p75). The significance of differences between median values was calculated using ANOVA for variables with normal distribution and Kruskal Wallis test for nonparametric variables. Linear regression equations were used to calculate the association between the presence of hypogonadism and the rest of variables. For estimation of fasting parameters of insulin resistance we used HOMA
TABLE 1: Variables expressed in average normal distribution and standard deviation. Nonnormal distribution variables, expressed as median and confidence interval.

\begin{tabular}{lc}
\hline$n$ & 101 \\
Age $(\mathrm{yr})$ & $38(17-60)$ \\
$\mathrm{IMC}\left(\mathrm{kg} / \mathrm{mt}^{2}\right)$ & $33 \pm 4.76$ \\
Waist $(\mathrm{cm})$ & $109(107-113)$ \\
Body fat $(\%)$ & $34.5 \pm 4.75$ \\
Body lean mass $(\%)$ & $30.9(30.2-31.4)$ \\
Visceral fat $(\%)$ & $16 \pm 4.26$ \\
Basal glycemia $(\mathrm{mmol} / \mathrm{L})$ & $5.32(5.21-5.38)$ \\
Postload glycemia $(\mathrm{mmol} / \mathrm{L})$ & $6.49(5.9-7.15)$ \\
Basal insulin $(\mathrm{mIU} / \mathrm{L})$ & $16.6(14.7-17.9)$ \\
Postload insulin $(\mathrm{mIU} / \mathrm{L})$ & $121(99-144)$ \\
HOMA & $3.8(3.5-4.2)$ \\
QUICKI & $0.31 \pm 0.024$ \\
Cholesterol (mmol/L) & $5.21 \pm 0.92$ \\
Cholesterol HDL $(\mathrm{mmol} / \mathrm{L})$ & $0.98(0.96-1.03)$ \\
Triglyceride $(\mathrm{mmol} / \mathrm{L})$ & $2.21(1.85-2.66)$ \\
Testosterone $(\mathrm{nmol} / \mathrm{L})$ & $12.4(11.8-13.4)$ \\
SHBG $(\mathrm{nmol} / \mathrm{L})$ & $24(22-25.6)$ \\
$\mathrm{c}$ free testosterone $(\mathrm{pg} / \mathrm{mL})$ & $89.9(38.2-170)$ \\
LH (mU/mL) & $4.28(3.6-4.78)$ \\
Estradiol $(\mathrm{pmol} / \mathrm{L})$ & $105(98.7-110.5)$ \\
TSH $(\mu \mathrm{IU} / \mathrm{mL})$ & $2.36(2.18-2.7)$ \\
Prolactin $(\mathrm{pmol} / \mathrm{L})$ & $435(378.2-448)$ \\
\hline
\end{tabular}

and QUICKI. Since all these parameters had different units of measure, no effort was made to carry out concordance analyses.

\section{Results}

The prevalence of hypotestosteronemia in our population was $17.8 \%$ with $\mathrm{T}$ and $20.7 \%$ with cf T. Of the total evaluated patients, 101 were selected for analysis. The characteristics of subjects are presented in Table 1 . The median age was 38 years, with an average BMI of $38 \mathrm{~kg} / \mathrm{m}^{2}$, no patient presented BMI within normal range, $28 \%$ were overweight, $63 \%$ were obese, and $9 \%$ had morbid obesity. With respect to waist circumference, only 27 patients $(26 \%)$ were within the normal range (less than $102 \mathrm{~cm}$ ).

When evaluating subjects according to presence or absence of $\mathrm{H}$, we found that the characteristics of the group varied according to the testosterone cut-off criteria used. When using T level under $10.4 \mathrm{nmol} / \mathrm{L}(300 \mathrm{ng} / \mathrm{dL})$, we noticed the $\mathrm{H}$ patients to have more visceral fat and insulin resistance indicators (QUICKI and HOMA), as well as presenting less LH, E2, and SHBG with significant differences with the non- $\mathrm{H}$ group (Table 2). When using a cfT cutoff of $72 \mathrm{pmol} / \mathrm{mL}$ we observed that the $\mathrm{H}$ group presented greater visceral fat, BMI, waist circumference, and rates of insulin resistance, with a stronger association than the $\mathrm{T}$ cutoff group, also showing lower levels of E2 and SHBG. With this cut-off point, statistical significance of LH levels is lost, 
TABLE 2: Variables expressed in average normal distribution \pm standard deviation analyzed by ANOVA. Nonnormal distribution variables, expressed as median + confidence interval, analyzed by Kruskal-Wallis test.

\begin{tabular}{|c|c|c|c|}
\hline Testosterone (cut-off $<10.4 \mathrm{nmol} / \mathrm{L})$ & Hypogonadism (18) & No hypogonadism (83) & $p$ \\
\hline Age (yr) & $45(31-55)$ & $37(34-40)$ & NS \\
\hline $\operatorname{IMC}\left(\mathrm{kg} / \mathrm{mt}^{2}\right)$ & $35 \pm 4.5$ & $33 \pm 4.7$ & NS \\
\hline Waist (cm) & $114 \pm 11$ & $108 \pm 10$ & NS \\
\hline Body fat (\%) & $35.5 \pm 4.8$ & $34 \pm 4.2$ & NS \\
\hline Body lean mass (\%) & $29 \pm 2.6$ & $30 \pm 2.5$ & NS \\
\hline Visceral fat (\%) & $18 \pm 4.4$ & $15 \pm 4.0$ & 0.003 \\
\hline Basal glycemia (mmol/L) & $5.49(4.99-5.71)$ & $5.27(5.21-5.38)$ & NS \\
\hline Postload glycemia (mmol/L) & $6.32 \pm 1.23$ & $7.10 \pm 2.22$ & NS \\
\hline Basal insulin (mIU/L) & $19.9(16-32)$ & $15.4(13-17)$ & 0.01 \\
\hline Postload insulin (mIU/L) & $107(92-218)$ & $127(97-152)$ & NS \\
\hline HOMA & $4.2(3.9-7.27)$ & $3.7(3.1-3.9)$ & 0.01 \\
\hline QUICKI & $0.31(0.29-0.31)$ & $0.32(0.31-0.32)$ & 0.02 \\
\hline Cholesterol (mmol/L) & $5.30 \pm 0.88$ & $5.18 \pm 0.98$ & NS \\
\hline Cholesterol HDL (mmol/L) & $0.89(0.88-0.98)$ & $0.89(0-93-1.26)$ & NS \\
\hline Triglyceride (mmol/L) & $2.40(1.67-3.46)$ & $2.20(1.70-2.67)$ & NS \\
\hline $\mathrm{c}$ free testosterone $(\mathrm{nmol} / \mathrm{L})$ & $16.3(12-20)$ & $25(23-27)$ & 0.001 \\
\hline SHBG (nmol/L) & $67 \pm 13$ & $96 \pm 22$ & 0.000 \\
\hline $\mathrm{LH}(\mathrm{mU} / \mathrm{mL})$ & $3.65(2.05-4.74)$ & $4.37(3.81-4.9)$ & 0.04 \\
\hline Estradiol (pmol/L) & $89.2(78.9-106)$ & $106.4(99-117.4)$ & 0.01 \\
\hline TSH $(\mu \mathrm{IU} / \mathrm{mL})$ & $2.4(1.6-2.88)$ & $2.35(2.14-2.88)$ & NS \\
\hline Prolactin (pmol/L) & $432(282-435)$ & $347(421-430)$ & NS \\
\hline
\end{tabular}

TABLE 3: Variables expressed in average normal distribution \pm standard deviation, analyzed by ANOVA. Nonnormal distribution variables, expressed as median + confidence interval, analyzed by Kruskall Wallis test.

\begin{tabular}{lccc}
\hline $\begin{array}{l}\text { c free testosterone } \\
\text { (cut-off }<72 \text { pmol/mL) }\end{array}$ & Hypogonadism (21) & No hypogonadism (80) & $p$ \\
\hline Age $(\mathrm{yr})$ & $41 \pm 13$ & $37 \pm 11$ & $\mathrm{NS}$ \\
IMC $\left(\mathrm{kg} / \mathrm{mt}^{2}\right)$ & $35 \pm 5.05$ & $32.9 \pm 4.5$ & 0.04 \\
Waist $(\mathrm{cm})$ & $114 \pm 11$ & $108 \pm 10$ & $\mathrm{NS}$ \\
Body fat $(\%)$ & $36 \pm 5.2$ & $34 \pm 4.5$ & $\mathrm{NS}$ \\
Body lean mass (\%) & $30(27-31.2)$ & $31.3(30-31.8)$ & 0.03 \\
Visceral fat $(\%)$ & $17.9 \pm 4.9$ & $15.4 \pm 3.9$ & 0.017 \\
Basal insulin $(\mathrm{mIU} / \mathrm{L})$ & $20.1(16-28)$ & $15.1(13.3-17.1)$ & 0.01 \\
HOMA & $4.55(3.9-6.3)$ & $3.7(3.0-3.9)$ & 0.01 \\
QUICKI & $0.30 \pm 0.02$ & $0.317 \pm 0.023$ & 0.034 \\
SHBG $(\mathrm{nmol} / \mathrm{L})$ & $16.4(13.7-19.8)$ & $25.5(23-27.9)$ & \\
LH $(\mathrm{mU} / \mathrm{mL})$ & $3.7(2.2-4.96)$ & $4.3(3.7-4.9)$ & \\
Estradiol $(\mathrm{pmol} / \mathrm{L})$ & $97.2(78.9-106.8)$ & $107(99-117.4)$ & 0.0001 \\
\hline
\end{tabular}

although they continue to be low (Table 3). While analyzing the composition of these groups, we observed that they were not composed of the same subjects, adding significance to the findings.

As seen in the tables, our population of hypogonadal subjects presented decreased levels of LH, a difference that is statistically significant, despite remaining within the ranges of normality of the measurement. We did not perceive an association between levels of $\mathrm{LH}$ and the rest of the variables analyzed. Once evaluating the association between the cfT and the rest of the variables, a weak but statistically significant correlation is noticeable with visceral fat percentage $(r-0.27$, $p 0.007)$ (Figure 1) and HOMA index $(r-0.20, p 0.04)$.

As expected, the relationship between testosterones and LH level is significant in the overall group $(r 0.76, p 0,000)$, if analyzed separating the hypo- versus normogonadal group (using different cut-off points); we find that despite remaining significant, the association is much more direct in the hypogonadal group (data not shown), correlation that is not modified when analyzed along with other factors. 
TABLE 4: Regression analysis is noted as the determinating variables of hypogonadism estradiol and 303 visceral fat. $R^{2} 0.10, p 0.02$.

\begin{tabular}{lcc}
\hline $\begin{array}{l}\text { Hypogonadism } \\
\text { (cut-off } \\
72 \text { pmol/mL) }\end{array}$ & Coefficient & $p>|t|$ \\
\hline Estradiol & -0.0071 & NS \\
Visceral fat & 0.0253 & 0.014 \\
Age & -0.0004 & NS \\
Constant & 0.0255 & NS \\
\hline
\end{tabular}

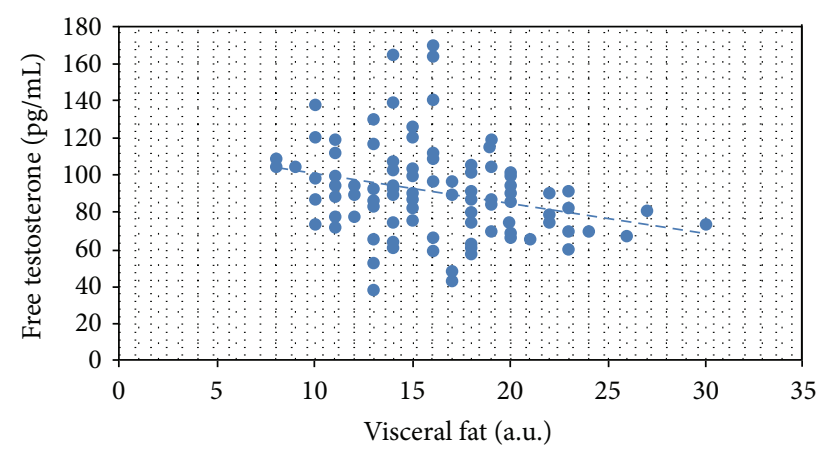

FIGURE 1: Relationship between visceral fat and free testosterone levels measured by impedance 299 measurement. $(r-0.28, p 0.01)$.

After performing linear regression analysis, we see that the levels of E2 and visceral fat are determining factors in the presence of $\mathrm{H}$, leaving the rest of the variables without statistical significance (Table 4). Furthermore, the correlation between the levels of E2 and the percentage of body fat and BMI is significant $(r 0.24, p 0.01$ and $r 0.26, p 0.01$, resp.), not detecting in this sample correlation between E2 levels and other biochemical parameters such as glycaemia, insulinemia, or cholesterol.

\section{Discussion}

Various studies have shown prevalence of $\mathrm{H}$, linked to obesity and diabetes, defined by low $\mathrm{T}$ with associated symptoms, in ranges from $17 \%$ to $30 \%[27,28]$, reaching up to $42 \%$ when considering levels of cfT [28]. Since Dhindsa et al. [29] published his study of $\mathrm{H}$ in T2DM, it has been shown that $\mathrm{H}$ is associated with diabetes, independent of adiposity. Suggesting that low androgen levels may be a risk factor for diabetes in men $[27,30]$. Our study population below 60 years of age presented $\mathrm{H}$ at a higher percentage than the general population, which is approximately $1.5 \%[31,32]$. In recent studies, the prevalence in healthy men above 60 years of age with late onset hypogonadism (LOH) is described to be between 2 and $4 \%[33,34]$. It is worth mentioning that our patients with MetS exhibit more $\mathrm{H}$ and earlier than the elder population. Several studies on nondiabetic obese patients show prevalence rates of $15 \%$ to $57 \%$ [14, 20, 35, 36].

The recognition and pursuit of $\mathrm{H}$ in young MetS carriers can be of great importance in identifying subpopulations with increased CVD risk, since $\mathrm{H}$ is considered another factor that complements CVD risk in the MetS $[1,37,38]$. Our series is the first to describe hypotestosteronemia as being related to MetS in an urban young male population of Chile.

The diagnosis of $\mathrm{H}$, in addition to decreased levels of $\mathrm{T}$, includes the existence of associated sexual symptoms. It is important to note that men with low $\mathrm{T}$ are not always symptomatic. A recent study determined the association between the MetS and T levels in patients with erectile dysfunction (ED) [39]; this study included 280 patients above 40 years of age, $16.4 \%$ had hypotestosteronemia and this was even more frequent in patients with MetS $(22.9 \%$ versus $11.7 \%$ ); however the presence of $\mathrm{H}$ was not decisive for the levels of symptomatic ED and the correlation was low between $\mathrm{T}$ levels and the occurrence of symptoms. The decline in $\mathrm{T}$ will therefore not always reflect on symptoms and it is not appropriate to wait for these to appear in order to search for hypotestosteronemia [38].

Although the pathophysiology of $\mathrm{H}$ in the MetS is not entirely clear, the inhibitory effect is preferably at a hypothalamic-pituitary level, but direct inhibitory effects on Leydig cell secretion have been described $[9,11]$. Our data support the hypothesis of a hypothalamic-pituitary effect because, in our group, the $\mathrm{H}$ patients presented lower values of $\mathrm{LH}$ and a negative correlation with the T compared to the non-H. Although age has a negative correlation, there are no significant differences between the ages of the $\mathrm{H}$ and the non$\mathrm{H}$.

It is noteworthy that the correlations of total and visceral fat were neither relevant nor significant and that there was only slightly positive one between the cfT and visceral fat measured by bioimpedanciometry. It is possible that the sensitivity of our bioimpedanciometry measuring instrument might have affected certain values, although it is a validated method [18, 40]. However the correlations with the waist measurement, weight, and BMI were also unimportant, although $\mathrm{H}$ patients were significantly more obese and had greater waist circumference and more insulin resistance, determined by values of basal insulin, HOMA, and QUICKI.

Androgen receptors are expressed in the visceral adipocytes, liver, and muscle among other tissues, determining tissue specific responses to androgens [32]; the dilemma of determining which is first, the $\mathrm{H}$, defined by hypotestosteronemia, or the increase in total and visceral fat, is not yet clear; however, in insulin resistance conditions, the inverse interaction between the visceral fat and $\mathrm{T}$ seems to increase $[7,11,41]$. Several factors have been studied: TNFa, adipokines, regulation of fat signal by neuropeptide $\mathrm{Y}$, and elevated leptin acting on hypothalamic kisspeptin which have been proposed as intermediaries in this connection [9]. Direct inhibitory effects of some of these factors on the Leydig cell, especially leptin and insulin, have also been suggested in this connection [42-44].

Insulin itself has direct hypothalamic axis stimulating effects in in vitro conditions [45]; however hyperinsulinemia has negative correlations with the $\mathrm{T}$ in vivo [46]. In our work we did not observe these relationships. In our study the values of E2 resulted in normal-low ranges for males, but significantly higher ones in non- $\mathrm{H}$ patients compared to $\mathrm{H}$, and the linear regression analysis showed that the E2 was one 
of the determinant variables of the presence of hypogonadism (Table 4). The increase in circulating and tissue-specific E2 due to increased aromatase activity is one of the etiological mechanisms associated with $\mathrm{H}$ in obese patients [35]. The INCHIANTI study [47], using 574 Italian patients above 65 years old, showed a positive association between the levels of E2 (total and free) with the components of the MetS, independent of age. Williams [48] in a recent article suggests that the activation of aromatase in tissues (FAT, breast) leads to an increase of cell E2, which along with increased insulin and leptin, could induce $\mathrm{H}$, metabolic syndrome, and mitogenic prostatic growth, via activation of estrogen receptors. It is possible that, in conditions of insulin resistance, the decrease of SHBG allows the presence of less plasmatic E2 but free E2 at a hypothalamic level acting as an LH inhibition factor and producing lower levels of testosterone. The role of E2 in men and its influence on the MetS are still unclear; yet we think that in our population it may itself be a determining factor. In conclusion, in our sample of young obese men, with metabolic syndrome, we identified a high prevalence of $\mathrm{H}$. These men turned out to be more insulin-resistant and have more visceral fat and greater waist circumference than the nonhypogonadal, although the correlations with the parameters of the Mets were not significant.

We believe that the search for $\mathrm{H}$ in young patients with MetS is fully justified given its high prevalence in different urban populations worldwide and the fact that it can identify a population with greater comorbidity and cardiovascular risk, especially with increasing age. Correction of the $\mathrm{H}$ and its role in the etiology of the MetS is pending evaluation, but it seems to open a very promising future in the reduction of morbidity.

\section{Conflict of Interests}

The authors declare that there is no conflict of interests regarding the publication of this paper.

\section{References}

[1] S. K. Singh, R. Goyal, and D. D. Pratyush, "Is hypoandrogenemia a component of metabolic syndrome in males?" Experimental and Clinical Endocrinology and Diabetes, vol. 119, no. 1, pp. 30-35, 2011.

[2] H. Beltrán-Sánchez, M. O. Harhay, M. M. Harhay, and S. McElligott, "Prevalence and trends of metabolic syndrome in the adult U.S. population, 1999-2010," Journal of the American College of Cardiology, vol. 62, no. 8, pp. 697-703, 2013.

[3] S. Chackrewarthy, D. Gunasekera, A. Pathmeswaren et al., "A comparison between revised NCEP ATP III and IDF definitions in diagnosing metabolic syndrome in an urban Sri Lankan population: the ragama health study," ISRN Endocrinology, vol. 2013, Article ID 320176, 7 pages, 2013.

[4] E. Acosta Garcia, "Vigencia del Síndrome Metabólico," Acta Bioquímica Clínica Latinoamericana, vol. 45, no. 3, 2011.

[5] J. Escobedo, H. Schargrodsky, B. Champagne et al., "Prevalence of the Metabolic Syndrome in Latin America and its association with sub-clinical carotid atherosclerosis: the CARMELA cross sectional study," Cardiovascular Diabetology, vol. 8, article 52, 2009.

[6] A. A. B. Valenzuela, A. Maíz, P. Margozzini et al., "Prevalencia de síndrome metabólico en población adulta Chilena: Datos de la Encuesta Nacional de Salud 2003," Revista Médica de Chile, vol. 138, pp. 707-714, 2010.

[7] P. M. Rao, D. M. Kelly, and T. H. Jones, “Testosterone and insulin resistance in the metabolic syndrome and T2DM in men," Nature Reviews Endocrinology, vol. 9, no. 8, pp. 479-493, 2013.

[8] P. R. Costanzo, S. M. Suárez, H. E. Scaglia, C. Zylbersztein, L. E. Litwak, and P. Knoblovits, "Evaluation of the hypothalamicpituitary-gonadal axis in eugonadal men with type 2 diabetes mellitus," Andrology, vol. 2, no. 1, pp. 117-124, 2014.

[9] A. Tchernof and J.-P. Després, "Pathophysiology of human visceral obesity: an update," Physiological Reviews, vol. 93, no. 1, pp. 359-404, 2013.

[10] S. Hajamor, J.-P. Després, C. Couillard et al., "Relationship between sex hormone-binding globulin levels and features of the metabolic syndrome," Metabolism: Clinical and Experimental, vol. 52, no. 6, pp. 724-730, 2003.

[11] D. E. Laaksonen, L. Niskanen, K. Punnonen et al., "Sex hormones, inflammation and the metabolic syndrome: a population-based study," European Journal of Endocrinology, vol. 149, no. 6, pp. 601-608, 2003.

[12] S. M. Gapstur, P. H. Gann, P. Kopp, L. Colangelo, C. Longcope, and K. Liu, "Serum androgen concentrations in young men: a longitudinal analysis of associations with age, obesity, and race. The CARDIA male hormone study," Cancer Epidemiology Biomarkers and Prevention, vol. 11, no. 10, pp. 1041-1047, 2002.

[13] G. B. Phillips, T. Jing, and S. B. Heymsfield, "Relationships in men of sex hormones, insulin, adiposity, and risk factors for myocardial infarction," Metabolism: Clinical and Experimental, vol. 52, no. 6, pp. 784-790, 2003.

[14] J. Hofstra, S. Loves, B. van Wageningen, J. Ruinemans-Koerts, I. Janssen, and H. de Boer, "High prevalence of hypogonadotropic hypogonadism in men referred for obesity treatment," Netherlands Journal of Medicine, vol. 66, no. 3, pp. 103-109, 2008.

[15] S. Y. Kalinchenko, Y. A. Tishova, G. J. Mskhalaya, L. J. G. Gooren, E. J. Giltay, and F. Saad, "Effects of testosterone supplementation on markers of the metabolic syndrome and inflammation in hypogonadal men with the metabolic syndrome: the double-blinded placebo-controlled Moscow study," Clinical Endocrinology, vol. 73, no. 5, pp. 602-612, 2010, Erratum to Clinical Endocrinology, vol. 75, no. 2, pp. 275, 2011.

[16] D. M. Kelly and T. H. Jones, "Testosterone: a vascular hormone in health and disease," Journal of Endocrinology, vol. 217, no. 3, pp. R47-R71, 2013.

[17] K. G. M. M. Alberti, P. Zimmet, and J. Shaw, "Metabolic syndrome-a new world-wide definition. A consensus statement from the International Diabetes Federation," Diabetic Medicine, vol. 23, no. 5, pp. 469-480, 2006.

[18] C. E. Ejike and I. I. Ijeh, "Obesity in young-adult Nigerians: variations in prevalence determined by anthropometry and bioelectrical impedance analysis, and the development of \% body fat prediction equations," International Archives of Medicine, vol. 5, article 22, 2012.

[19] V. Martín Moreno, B. Gómez Gandoy, M. Antoranz González, S. Fernández Herranz, A. Gómez De La Cámara, and M. de Oya Otero, "Validation of the OMRON BF 300 monitor 
for measuring body fat by bioelectric impedance," Atencion Primaria, vol. 28, no. 3, pp. 174-181, 2001.

[20] L. P. Ly, G. Sartorius, L. Hull et al., "Accuracy of calculated free testosterone formulae in men," Clinical Endocrinology, vol. 73, no. 3, pp. 382-388, 2010.

[21] http://www.issam.com/free\%20calculator\%20testosterone.

[22] S. Bashin, M. Pencina, G. K. Jasuja et al., "Reference ranges for testosterone in men generated using liquid chromatography tandem mass spectrometry in a community-based sample of healthy nonobese young men in the framingham heart study and applied to three geographically distinct cohorts," The Journal of Clinical Endocrinology \& Metabolism, vol. 96, no. 8, pp. 2430-2439, 2011.

[23] D. A. Paduch, R. E. Brannigan, E. F. Fuchs, E. D. Kim, J. L. Marmar, and J. I. Sandlow, "The laboratory diagnosis of testosterone deficiency," Urology, vol. 83, no. 5, pp. 980-988, 2014.

[24] A. Vermeulen, L. Verdonck, and J. M. Kaufman, "A critical evaluation of simple methods for the estimation of free testosterone in serum," Journal of Clinical Endocrinology and Metabolism, vol. 84, no. 10, pp. 3666-3672, 1999.

[25] J. Rodríguez Tolrà, A. Domínguez García, J. Torremadé Barreda, D. Rodríguez Pérez, and E. Franco Miranda, "Importance of calculated free testosterone in the diagnosis of testosterone deficiency syndrome," Revista Internacional de Andrologia, vol. 8, no. 2, pp. 85-88, 2010.

[26] W. A. Herman, A. Krzoska, E. Pawliczak, M. Roszak, and K. Łacka, "Evaluation of relationships between plasma androgens level and clinical signs of hipoandrogenism according to age and comorbidity of metabolic syndrome in men," Polski Merkuriusz Lekarski, vol. 36, no. 211, pp. 16-21, 2014.

[27] D. Kapoor, H. Aldred, S. Clark, K. S. Channer, and T. H. Jones, "Clinical and biochemical assessment of hypogonadism in men with type 2 diabetes: correlations with bioavailable testosterone and visceral adiposity," Diabetes Care, vol. 30, no. 4, pp. 911-917, 2007.

[28] O. A. Ogbera, C. Sonny, F. Olufemi, and A. Wale, "Hypogonadism and subnormal total testosterone levels in men with type 2 diabetes mellitus," Journal of the College of Physicians and Surgeons Pakistan, vol. 21, no. 9, pp. 517-521, 2011.

[29] S. Dhindsa, S. Prabhakar, M. Sethi, A. Bandyopadhyay, A. Chaudhuri, and P. Dandona, "Frequent occurrence of hypogonadotropic hypogonadism in type 2 diabetes," Journal of Clinical Endocrinology and Metabolism, vol. 89, no. 11, pp. 5462-5468, 2004.

[30] E. Selvin, M. Feinleib, L. Zhang et al., "Androgens and diabetes in men: results from the Third National Health and Nutrition Examination Survey (NHANES III)," Diabetes Care, vol. 30, no. 2, pp. 234-238, 2007.

[31] A. Gray, H. A. Feldman, J. B. McKinlay, and C. Longcope, "Age, disease, and changing sex hormone levels in middle-aged men: results of the Massachusetts male aging study," Journal of Clinical Endocrinology and Metabolism, vol. 73, no. 5, pp. 10161025, 1991.

[32] G. R. Dohle, S. Arver, C. Bettocchi, S. Kliesch, M. Punab, and W. de Ronde, Guidelines on Male Hypogonadism, European Association of Urology, Arnhem, The Netherlands, 2012.

[33] A. Tajar, I. T. Huhtaniemi, T. W. O’Neill et al., "Characteristics of androgen deficiency in late-onset hypogonadism: results from the European Male Aging Study (EMAS)," The Journal of
Clinical Endocrinology \& Metabolism, vol. 97, no. 5, pp. 15081516, 2012.

[34] R. Haring, T. Ittermann, H. Völzke et al., "Prevalence, incidence and risk factors of testosterone deficiency in a population-based cohort of men: results from the study of health in Pomerania," Aging Male, vol. 13, no. 4, pp. 247-257, 2010.

[35] A. Gatti, E. Mandosi, M. Fallarino et al., "Metabolic syndrome and erectile dysfunction among obese non-diabetic subjects," Journal of Endocrinological Investigation, vol. 32, no. 6, pp. 542345, 2009.

[36] B. D. Anawalt, J. M. Hotaling, T. J. Walsh, and A. M. Matsumoto, "Performance of total testosterone measurement to predict free testosterone for the biochemical evaluation of male hypogonadism," Journal of Urology, vol. 187, no. 4, pp. 1369-1373, 2012.

[37] M. Grossmann, M. C. Thomas, S. Panagiotopoulos et al., "Low testosterone levels are common and associated with insulin resistance in men with diabetes," Journal of Clinical Endocrinology and Metabolism, vol. 93, no. 5, pp. 1834-1840, 2008.

[38] M. Biswas, D. Hampton, R. G. Newcombe, and D. A. Rees, "Total and free testosterone concentrations are strongly influenced by age and central obesity in men with type 1 and type 2 diabetes but correlate weakly with symptoms of androgen deficiency and diabetes-related quality of life," Clinical Endocrinology, vol. 76, no. 5, pp. 665-673, 2012.

[39] Y. Aslan, O. Guzel, M. Balci, A. Tuncel, M. Yildiz, and A. Atan, "The impact of metabolic syndrome on serum total testosterone level in patients with erectile dysfunction," Aging Male, vol. 17, no. 2, pp. 76-80, 2014.

[40] C. Verdich, P. Barbe, M. Petersen et al., "Changes in body composition during weight loss in obese subjects in the NUGENOB study: comparison of bioelectrical impedance vs. dual-energy X-ray absorptiometry," Diabetes and Metabolism, vol. 37, no. 3, pp. 222-229, 2011.

[41] M. Garaulet, F. Perez-Llamas, T. Fuente, S. Zamora, and F. J. Tebar, "Anthropometric, computed tomography and fat cell data in an obese population: relationship with insulin, leptin, tumor necrosis factor-alpha, sex hormone-binding globulin and sex hormones," European Journal of Endocrinology, vol. 143, no. 5, pp. 657-666, 2000.

[42] M. Tena-Sempere, L. Pinilla, L. C. González, C. Diéguez, F. F. Casanueva, and E. Aguilar, "Leptin inhibits testosterone secretion from adult rat testis in vitro," Journal of Endocrinology, vol. 161, no. 2, pp. 211-218, 1999.

[43] A. M. Isidori, M. Caprio, F. Strollo, C. Moretti, G. Frajese, and A. Fabbri, "Leptin and androgens in male obesity: evidence for leptin contribution to reduced androgen levels," Journal of Clinical Endocrinology and Metabolism, vol. 84, no. 10, pp. 36733680, 1999.

[44] N. Pitteloud, M. Hardin, A. A. Dwyer et al., "Increasing insulin resistance is associated with a decrease in Leydig cell testosterone secretion in men," The Journal of Clinical Endocrinology \& Metabolism, vol. 90, no. 5, pp. 2636-2641, 2005.

[45] J. C. Bruning, D. Gautam, D. J. Burks et al., "Role of brain insulin receptor in control of body weight and reproduction," Science, vol. 289, no. 5487, pp. 2122-2125, 2000.

[46] T. Lin, J. Haskell, N. Vinson, and L. Terracio, "Characterization of insulin and insulin-like growth factor I receptors of purified Leydig cells and their role in steroidogenesis in primary culture: a comparative study," Endocrinology, vol. 119, no. 4, pp. 1641$1647,1986$. 
[47] M. Maggio, F. Lauretani, G. P. Ceda et al., "Estradiol and metabolic syndrome in older Italian men: the InCHIANTI study," Journal of Andrology, vol. 31, no. 2, pp. 155-162, 2010.

[48] G. Williams, "Aromatase up-regulation, insulin and raised intracellular oestrogens in men, induce adiposity, metabolic syndrome and prostate disease, via aberrant ER- $\alpha$ and GPER signalling," Molecular and Cellular Endocrinology, vol. 351, no. 2, pp. 269-278, 2012. 


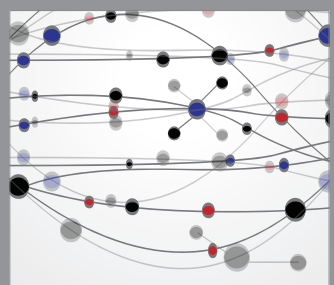

The Scientific World Journal
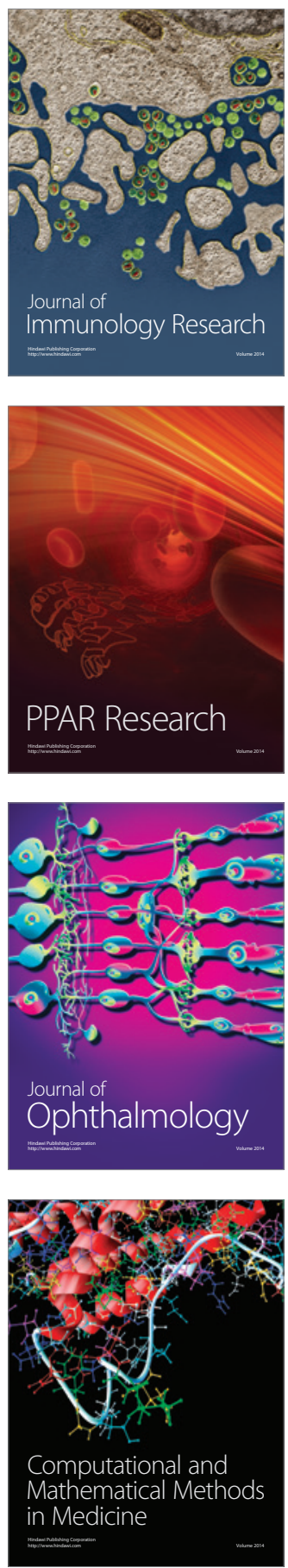

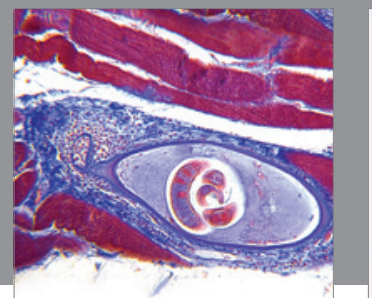

Gastroenterology

Research and Practice
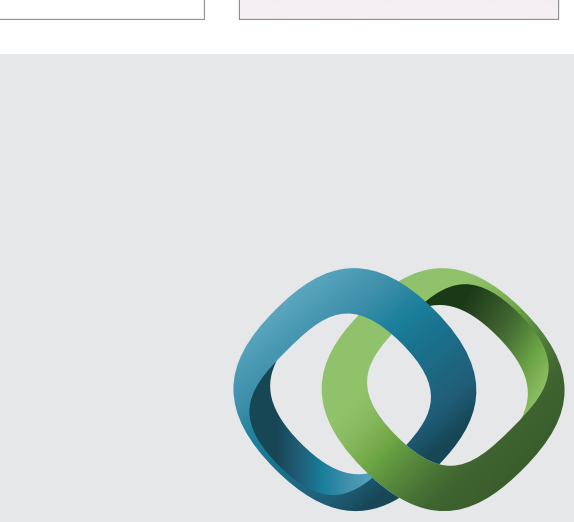

\section{Hindawi}

Submit your manuscripts at

http://www.hindawi.com
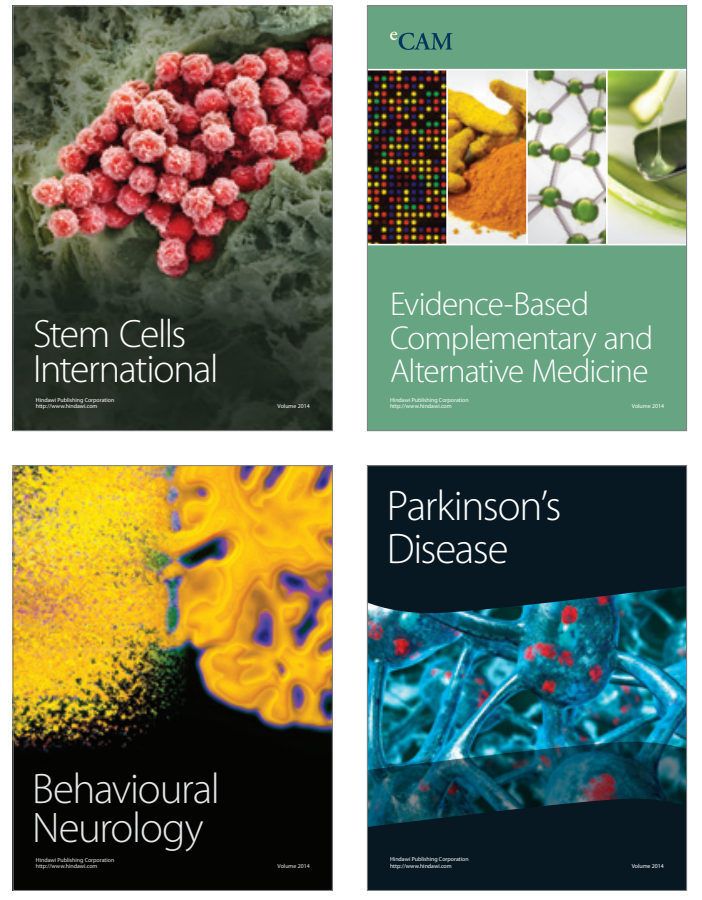
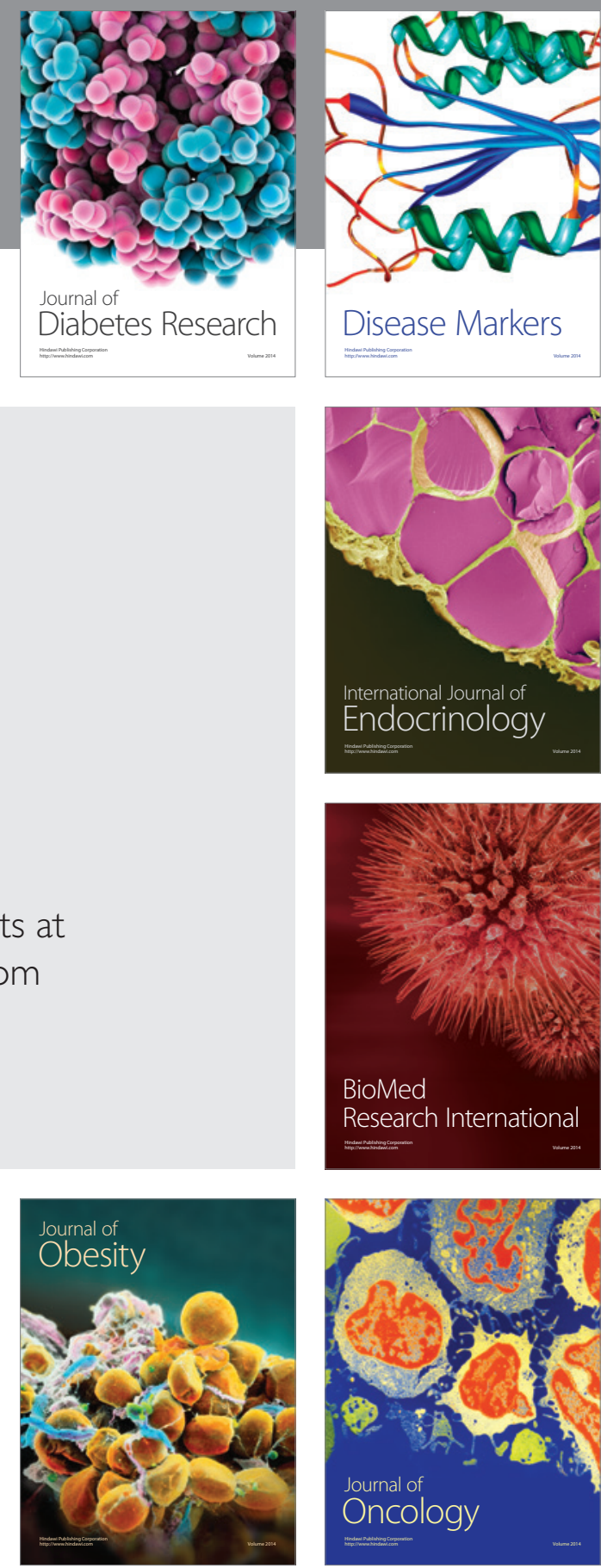

Disease Markers
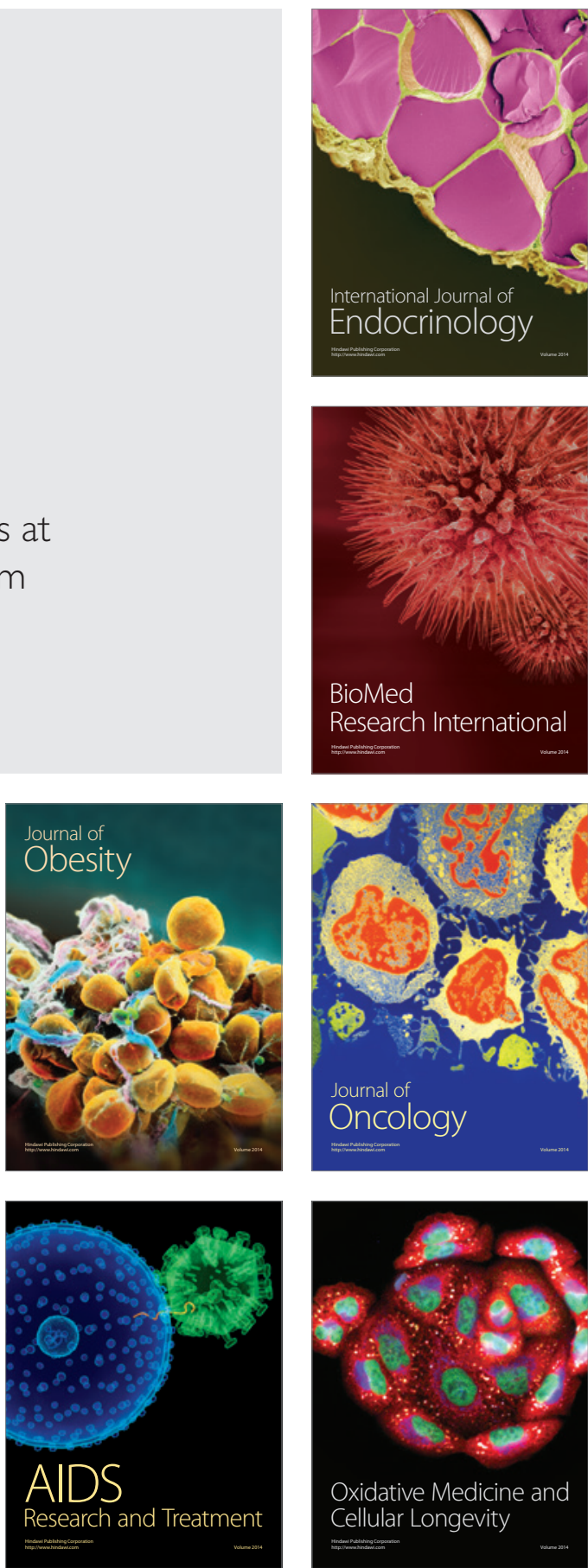